\title{
Secondary Abnormal CSF Neurotransmitter Metabolite Profiles in a Pediatric Tertiary Care Centre
}

\author{
Clara D.M. van Karnebeek, Mary Dunbar, Csilla Egri, Bryan Sayson, \\ Janetta Milea, Sylvia Stockler-Ipsiroglu, Linda Huh, Mary B. Connolly, \\ Gabriella A. Horvath
}

\begin{abstract}
Background: Secondary neurotransmitter deficiencies have been reported in several reviews. Our primary aim was to assess the relationship among epilepsy, antiseizure medications, and specific neurotransmitter abnormalities. We also evaluated movement disorders and brain abnormalities via magnetic resonance imaging scans in patients with secondary neurotransmitter defects. Methods: This is a retrospective case series of 376 patients who underwent neurotransmitter analysis at BC Children's Hospital between 2009 and 2013, for a variety of neurological presentations. The biochemical genetics laboratory database was interrogated for results of cerebrospinal fluid neurotransmitter analyses. Clinical data for patients with abnormal results were collected from the hospital charts. Statistical analysis included one-way analysis of variance, chi-square, and a two-way contingency table. Results: Abnormal neurotransmitter values were identified in $67(17.8 \%)$ patients, two $(0.53 \%)$ of which were attributable to a congenital neurotransmitter disorder and $11(16.9 \%)$ secondary to other genetic diagnoses. Of 64 patients with secondary abnormal neurotransmitter values, 38 (59\%) presented with epilepsy and $20(31 \%)$ with movement disorders. A combination of epilepsy and movement disorder was less frequent. Discussion: Acknowledging the limitations of this retrospective chart review, we conclude that, in our cohort, in addition to patients with movement disorders, a considerable number of patients with epilepsy and epileptic encephalopathy also showed secondary neurotransmitter mono-amine abnormalities. There is no clear relation, however, between clinical phenotype and type of neurotransmitter affected. In addition, no association was identified between the type of antiseizure medications and affected neurotransmitter type. We outline the need for prospective studies to further enrich our understanding of the relation between epilepsy and neurotransmitters with a focus on improving treatments and patient outcomes.
\end{abstract}

RÉSUMÉ: Profiles anormaux secondaires des métabolites de neurotransmetteurs dans le LCR, mesurés dans un centre de soins pédiatriques tertiaires. Contexte: Des déficits secondaires de neurotransmetteurs ont été rapportés dans plusieurs articles de revue. Notre but principal était d'évaluer la relation entre l'épilepsie, les médicaments antiépileptiques et des anomalies spécifiques des neurotransmetteurs. Nous avons également évalué les désordres du mouvement et les anomalies cérébrales par imagerie par résonance magnétique chez des patients ayant des anomalies secondaires des neurotransmetteurs. Méthodologie: Nous présentons une étude rétrospective de 376 patients qui ont subi une analyse des neurotransmetteurs au BC Children's Hospital entre 2009 et 2013. Ces patients présentaient différents problèmes neurologiques. Nous avons identifié les résultats des analyses de neurotransmetteurs du liquide céphalorachidien dans la base de données du laboratoire de génétique biochimique. Les données cliniques des patients ayant des résultats anormaux ont été recueillies dans les dossiers hospitaliers. Les analyses statistiques suivantes ont été utilisées: l'analyse de variance à un critère de classification, le chi-carré et le tableau de contingence à double entrée. Résultats: Des valeurs anormales de neurotransmetteurs ont été identifiées chez $67(17,8 \%)$ des patients, dont deux $(0,53 \%)$ étaient attribuables à une maladie congénitale des neurotransmetteurs et $11(16,9 \%)$ étaient secondaires à d'autres diagnostics génétiques. Parmi les 64 patients ayant des valeurs de neurotransmetteurs anormales secondaires, 38 (59\%) avaient consulté pour épilepsie et 20 (31\%) pour des troubles du mouvement. Une combinaison d'épilepsie et de trouble du mouvement était moins fréquente. Discussion: Tout en reconnaissant les limites de cette revue rétrospective de dossiers, nous concluons que dans notre cohorte, en plus des patients ayant des troubles du mouvement, un nombre appréciable de patients atteints d'épilepsie et d'encéphalopathie épileptique avaient aussi des anomalies secondaires des neurotransmetteurs de type monoamine. Cependant, il n'existe pas de relation claire entre le phénotype clinique et le type de neurotransmetteur touché.

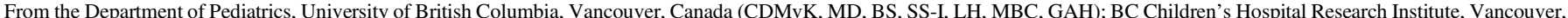

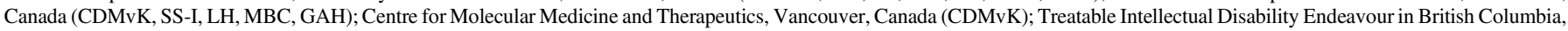

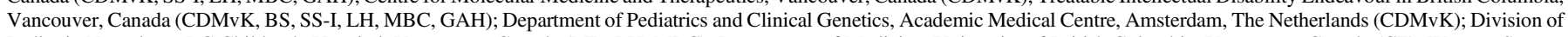

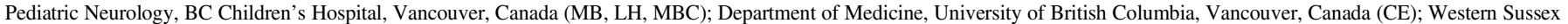
Hospitals NHS Foundation Trust, United Kingdom (JM); Division of Biochemical Diseases, BC Children's Hospital, Vancouver, Canada (SS-I, GAH).

CDMvK and MB contributed equally to this work.

Received June 25, 2016. Final Revisions Submitted August 10, 2017. Date of Acceptance September 6, 2017.

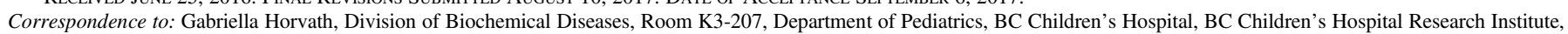
University of British Columbia, 4480 Oak Street, Vancouver, BC V6H 3V4, Canada. Email: ghorvath@cw.bc.ca 
De plus, nous n'avons pas identifié d'association entre le type de médication antiépileptique et le type de neurotransmetteur anormal. Nous soulignons qu'il sera nécessaire de procéder à des études prospectives afin de parfaire notre compréhension de la relation entre l'épilepsie et les neurotransmetteurs, en mettent l'emphase sur l'amélioration du traitement et des résultats pour les patients.

Keywords: dopamine, epileptic encephalopathy, epilepsy, serotonin, neurotransmitters

doi:10.1017/cjn.2017.271

Can J Neurol Sci. 2018; 45: 206-213

Congenital neurotransmitter disorders result from abnormalities in their synthesis or metabolism. The most commonly measured cerebrospinal fluid (CSF) neurotransmitters are the biogenic amines (dopamine and serotonin) and their metabolites (respectively homovanillic acid [HVA] and 5-hydroxyindoleacetic acid [5HIAA]). Inherited disorders of neurotransmitter synthesis can be caused either by a defect in the synthetic enzyme or in one of the cofactors that activate these enzymes, such as tetrahydrobiopterin (Figure 1) as well as pyridoxal phosphate. The latter is the cofactor for the enzyme aromatic L-amino acid decarboxylase, is deficient in PNPO deficiency, and will mimic the findings of primary AADC deficiency. Measuring CSF pterins helps differentiate between a neurotransmitter synthesis defect versus a tetrahydrobiopterin deficiency.

Patients with congenital neurotransmitter diseases present with movement disorders, developmental delay, autonomic features (excessive sweating, salivation, and aberrant temperature control) and axial hypotonia. ${ }^{1}$ Combinations of these symptoms can masquerade as more common neurological conditions such as cerebral palsy ${ }^{2}$ and hypoxic ischemic encephalopathy, ${ }^{3}$ but because the majority of the inherited neurotransmitter disorders are treatable, recognition of these disorders is crucial.

Secondary disturbances in monoamine levels have been reported in other medical or genetic conditions and may contribute to morbidity. ${ }^{4}$ They may be present in acquired central nervous system injuries, some genetic syndromes and inborn errors of metabolism other than congenital neurotransmitter disorders,

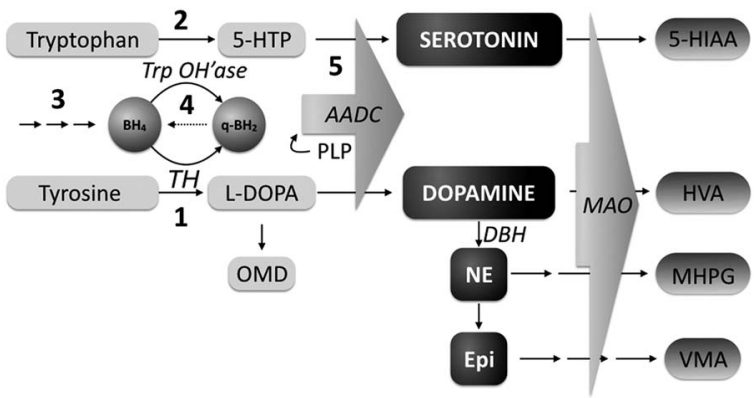

Figure 1: Monoamine synthesis and metabolism.

BH4 = tetrahydrobiopterin; $\quad q-\mathrm{BH} 2=q$-dihydrobiopterin; $\quad$ TrpOH'ase =tryptophan hydroxylase; $T H=$ tyrosine hydroxylase; $5-H T P=$ 5-hydroxytryptophan; $O M D=3-O$-methyldopa; $\quad A A D C=$ aromatic L-amino acid decarboxylase; $D A=$ dopamine; $N E=$ norepinephrine; $E P I=$ epinephrine $; \mathrm{DBH}=$ dopamine beta-hydroxylase $; M A O=$ monamine oxidase; 5-HIAA = 5-hydroxyindole acetic acid; $H V A=$ homovanillic acid; $M H P G=3-m e t h o x y-4-h y d r o x y p h e n y l g l y c o l ; P L P=$ pyridoxal 5'-phosphate; $V M A=$ vanilymandelic acid; 1: Tyrosine Hydroxylase deficiency; 2: Tryptophan hydroxylase deficiency; 3: Biopterin synthesis disorders (GTPCH, PTPS, SR); 4: Biopterin recycling defect (DHPR); 5: Aromatic amino acid decarboxylase deficiency, pyridoxal 5'-phosphate deficiency. (Adapted from Pearl 2007) epilepsy, and epileptic encephalopathy. ${ }^{5-8}$ The mechanisms and approach to treatment of these secondary disorders of neurotransmission have only recently begun to be explored. ${ }^{3,24}$

Epilepsy affects $1 \%$ of the population, ${ }^{9}$ and it has been described to be associated with altered levels of monoamine neurotransmitters. ${ }^{10-12}$ Possible mechanisms underlying altered monoamine metabolism include focal or general cerebral and neuronal dysfunction, supported by studies demonstrating postictal changes but normal interictal levels. ${ }^{13}$ This suggests that the CSF of patients who have very frequent seizures and epileptic encephalopathy may demonstrate the most severe perturbations in monoamines. Often, reference laboratories attribute abnormal CSF monoamine neurotransmitter results, if pterins are normal, as secondary to seizures, hypoxia, or antiseizure medications.

The British Columbia Children's Hospital in Vancouver is a tertiary care facility serving the entire province of nearly one million children, with numerous referrals of children with complex, diagnostically challenging neurological disorders. Many of these children undergo a lumbar puncture during their diagnostic workup, and our center historically has been sending samples for CSF neurotransmitter analysis to Dr. Keith Hyland at the Medical Neurogenetics Laboratory in Atlanta, GA since 2003. In 2008, we conducted a retrospective chart review of all CSF neurotransmitter results collected in the previous 4 years. Of the 259 patients who underwent CSF neurotransmitter analysis between 2005 and 2008, 140 patients showed abnormal results; of these, five $(1.9 \%)$ were diagnosed with a congenital neurotransmitter disorder (data not published).

The dataset we present in this paper pertains to a second retrospective chart review performed in 2014, analyzing data from the previous 5 years, focusing on possible associations between CSF monoamines and neurologic features, including epilepsy, movement disorders, and magnetic resonance imaging (MRI) changes. This is the dataset that we present in this paper.

\section{Methods \\ Data Collection}

The Biochemical Genetics Laboratory database at British Columbia Children's Hospital was reviewed for results of all CSF neurotransmitter (NT) analyses performed between 2009 and 2013. The NT analyses was performed in the Medical Neurogenetics Lab as described by Hyland et al. ${ }^{14,15}$ Clinical data on patients found to have abnormal results were collected from the BC Children's Hospital, Pediatric Neurology and Biochemical Diseases Clinic charts.

\section{Definitions}

Abnormal values of NT metabolites were identified as HVA and 5-HIAA above or below the age-standardized normal values. 
Table 1: Characteristics of patients with secondary CSF neurotransmitter abnormalities

\begin{tabular}{|c|c|c|c|c|c|c|c|c|c|c|}
\hline \multirow[b]{2}{*}{ Low HVA } & \multirow{2}{*}{$\begin{array}{l}\mathbf{N} \\
27\end{array}$} & \multirow{2}{*}{$\begin{array}{c}\begin{array}{c}\text { Mean \% limit of } \\
\text { normal value }\end{array} \\
84.7 \%\end{array}$} & \multirow{2}{*}{$\begin{array}{c}\begin{array}{c}\text { Mean Age } \\
\text { (years) }\end{array} \\
4.9\end{array}$} & \multirow{2}{*}{$\begin{array}{c}\begin{array}{c}\text { Male } \\
(\%)\end{array} \\
41 \%\end{array}$} & \multicolumn{2}{|c|}{$\begin{array}{c}\text { Epilepsy } \\
(\%)\end{array}$} & \multicolumn{2}{|c|}{$\begin{array}{c}\text { Movement } \\
\text { disorder (\%) }\end{array}$} & \multicolumn{2}{|c|}{$\begin{array}{l}\text { Abnormal } \\
\text { MRI (\%) }\end{array}$} \\
\hline & & & & & 18 & $(67 \%)$ & 6 & $(22 \%)$ & 16 & $(59 \%)$ \\
\hline Low 5-HIAA & 9 & $88.1 \%$ & 7.9 & $22 \%$ & 6 & $(67 \%)$ & 2 & $(22 \%)$ & 6 & $(67 \%)$ \\
\hline Low HVA, 5-HIAA & 18 & $71.1 \%, 70.9 \%$ & 11.5 & $53 \%$ & 8 & $(44 \%)$ & 8 & $(42 \%)$ & 9 & $(50 \%)$ \\
\hline Low 5-MTHF & 6 & $85.7 \%$ & 8.6 & $33 \%$ & 4 & $(67 \%)$ & 2 & $(33 \%)$ & 2 & $(33 \%)$ \\
\hline Low 5-MTHF, HVA & 2 & $\begin{array}{l}90.3 \% \\
67.5 \%\end{array}$ & 7.7 & $50 \%$ & 1 & $(50 \%)$ & 1 & $(50 \%)$ & 1 & $(50 \%)$ \\
\hline Low HVA, 5-HIAA, 5-MTHF & 2 & $\begin{array}{l}65.1 \% \\
70.3 \% \\
86.3 \%\end{array}$ & 12.7 & $50 \%$ & 1 & $(100 \%)$ & 1 & $(50 \%)$ & 2 & $(100 \%)$ \\
\hline Total & 64 & & 7.8 & $40 \%$ & 38 & $(59 \%)$ & 20 & $(31 \%)$ & 37 & $(56 \%)$ \\
\hline
\end{tabular}

Cerebral folate (5-methyltetrahydrofolate [5MTHF]) values were added because of the high prevalence of abnormal results and because it is included in the standard NT report from the Hyland Lab. Results were categorized into six groups (Tables 1 and 2) based on the various combinations of the three metabolites.

Congenital neurotransmitter disorders suggested by the neurotransmitter abnormalities in a pattern consistent with a particular enzyme deficiency in the biogenic amine synthesis, or pterin synthesis and recycling pathways, were confirmed genetically. ${ }^{16}$ Results of abnormal CSF levels of HVA, 5HIAA, and 5MTHF, in which CSF pterin analysis was normal, were considered secondary.

Epilepsy was defined as two or more unprovoked seizures occurring greater than 24 hours apart. ${ }^{17}$ Seizures were classified according to the International League Against Epilepsy definitions into epileptic spasms, focal seizures, or general seizures. ${ }^{18}$ Given the hypothesis that epileptic encephalopathy may contribute most to monoamine abnormalities, any patient with epileptic encephalopathy was categorized as such. Seizures were analyzed in three groups (Figure 2). In addition, several patients experienced febrile seizures and did not develop epilepsy. Seizures were documented during electroencephalograph (EEG) examination in 23 of 38 patients. Epilepsy was characterized as well-controlled or treatment-resistant. Well-controlled was defined as seizure-free for longer than 1 year at most recent follow-up. Treatment-resistant epilepsy was defined as ongoing seizures despite trial of at least two appropriate antiseizure medications. ${ }^{19}$ Seizure control was designated "unclear" if there was a lack of EEG or clinical followup, or difficulties with medication compliance. Epileptic encephalopathy was established when intractable epilepsy lead to global developmental delay and cognitive dysfunction. ${ }^{18}$

\section{Neuroimaging}

Patients underwent MRI scans with T1, T2, and fluidattenuated inversion recovery sequences and often magnetic resonance spectroscopy.

\section{Ethics}

The study was approved by the Regional Ethics Board, BC Children's Hospital, University of British Columbia (H11-01142).

\section{Data Collection and Extraction}

Patients' records were reviewed for: age at presentation, family history, consanguinity, microcephaly, developmental delay, autism, behavior, movement disorder type, pyramidal signs, hypotonia,

Table 2: Types of Neurotransmitter abnormalities and associated genetic diagnoses and conditions

\begin{tabular}{|c|c|c|c|}
\hline & & \multicolumn{2}{|l|}{ Secondary } \\
\hline & $\mathbf{n}$ & Genetic diagnosis & Associated conditions \\
\hline Low HVA & 27 & $\begin{array}{l}\text {-FOXG1 mutation } \\
\text {-DYRK1A mutation } \\
\text {-SCN1A mutation and TSC1 mutation } \\
\text {-Copy gain of } 5.79 \mathrm{Mb} \text { at } 15 \mathrm{q} 11.2 \mathrm{q} 13.1\end{array}$ & $\begin{array}{l}\text {-PEHO } \\
\text {-Focal cortical dysplasia } \\
\text {-Herpes simplex virus } 2 \text { encephalitis }\end{array}$ \\
\hline Low 5-HIAA & 9 & -Copy gain of $581 \mathrm{~Kb}$ at $19 \mathrm{p} 11 \mathrm{p} 12$; copy gain of $2.5 \mathrm{Mb}$ at $21 \mathrm{q} 11.21$ & \\
\hline Low HVA, 5-HIAA & 18 & $\begin{array}{l}\text {-non-ketotic hyperglycinemia (homozygous } G L D C \text { gene deletion) } \\
\text {-Chromosome } 10 \text { deletion at } 10 \mathrm{q} 26.2-10 \mathrm{q} 26.3,6.42 \mathrm{Mb} \\
\text {-SCN2A mutation }\end{array}$ & $\begin{array}{l}\text {-Focal cortical dysplasia type } 1 \text { and } 2 \\
\text {-Severe HIE } \\
\text {-T-cell ALL }\end{array}$ \\
\hline Low 5-MTHF & 6 & -Hereditary sensory autonomic neuropathy (type $2 \mathrm{~B} ; F A M 134 B$ ) and $D N M L 1$ mutation & \\
\hline Low 5-MTHF, HVA & 2 & & -Folate receptor antibodies \\
\hline Low HVA, 5-HIAA, 5-MTHF & 2 & $-C T S B$ gene mutation (2 siblings) & -HIE \\
\hline
\end{tabular}

$\mathrm{HIE}=$ hypoxic ischemic encephalopathy, ALL = acute lymphoblastic leukemia, $\mathrm{PEHO}=$ progressive encephalopathy with edema, hypsarrhythmia, and optic atrophy 


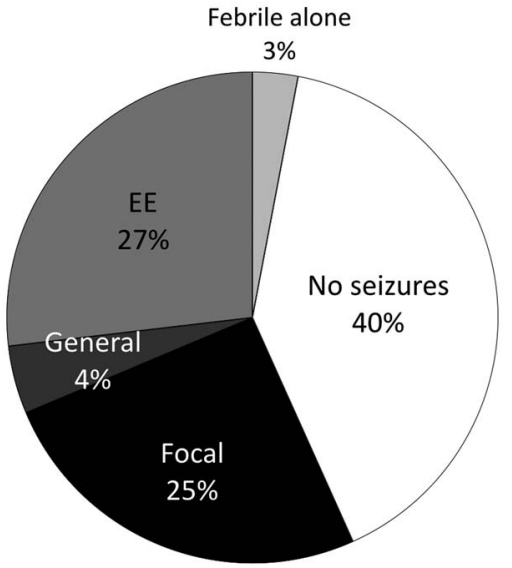

Figure 2: Percentage of patients without seizures and with each seizure subtype.

$E E=$ epileptic encephalopathy

presence of seizures, seizure type, seizure control, antiseizure medications and other therapies, CSF neurotransmitter abnormality, neuroimaging findings, primary genetic diagnosis if any, and outcome.

\section{Patient Selection}

In this review, all patients with congenital neurotransmitter disorders were excluded because the focus of this study was on the secondary deficiencies. Because collection of CSF NT requires following a strict protocol, if the collection method was recognized to be substandard, those patients were excluded from further analysis. In addition, patients on treatment with L-dopa or selective serotonin reuptake inhibitors at the time of CSF collection were excluded.

\section{Statistics}

For each patient, a value was generated as a percent of the lower limit of normal value. These were compared for significance between groups using a one-way analysis of variance.

Significant differences between means were determined using a one-way analysis of variance test with alpha $=0.05$ and a post hoc Scheffe test with PSPP software. Significance of categorical probabilities was determined with a chi-square test alpha $=0.05$ or a two-way contingency table. Significance was achieved with a $\mathrm{p}<0.05$. Odds ratios were calculated for significant results.

\section{RESULTS}

The database search identified 376 patients from 2009 through 2013 who were tested for disorders of neurotransmission, of which 72 had possible abnormal NT results. Two patients $(0.53 \%)$ were diagnosed with a congenital neurotransmitter disorder (tyrosine hydroxylase deficiency). These two patients were excluded from the remainder of the analysis. Five additional patients were excluded: two because of poor collection techniques, two because of L-dopa supplementation before testing, and two who received a selective serotonin reuptake inhibitor. According to our criteria, $64(17 \%)$ patients were identified with secondary abnormal values of HVA, 5-HIAA, and/or MTHF (Table 1).

Five patients are known to be deceased. Causes of or circumstances at death included cardiac arrest at age 3 years with severe neurodevelopmental delay and dysmorphic features, herpes simplex virus 2 encephalitis at 2 months, death at 3 days of age with epileptic encephalopathy, death at 1 month with severe neuromuscular weakness, profound hypoxic ischemic encephalopathy in an unidentified syndrome with dysmorphic features, and death at age 2 years.

Of the 64 patients with secondary abnormal neurotransmitter values, $11(17 \%)$ were diagnosed with a genetic condition accounting for some or all of their symptoms (Table 2). Average values of HVA and 5-HIAA for deficient patients ranged from $33.2 \%$ to $98.6 \%$ (HVA) and $23.8 \%$ to $98.4 \%$ (5-HIAA) of the lower limit of normal and from $75 \%$ (HVA) to $82 \%$ (5-HIAA) for those deficient in both HVA and 5-HIAA.

Thirty-eight patients (59\%) had epilepsy (Table 1). The proportion of patients in each epilepsy subgroup is shown in Figure 2. There was no significant difference in the prevalence of epilepsy between neurotransmitter deficiencies or between neurotransmitter deficiencies and epilepsy subgroups. Of the 38 patients with seizures, 20 were controlled by medication at most recent follow-up (51.2\%). Epilepsy type and neurotransmitter deficiency did not predict seizure control. Nine different antiseizure medications were used in mono or multitherapy (Table 3).

Of 64 patients with abnormal neurotransmitters, $32(50 \%)$ presented with seizures without movement disorder, $14(22 \%)$ had movement disorder without seizures, $6(9 \%)$ had both seizures and movement disorder, and 14 (22\%) had neither (Figure 3 ). The patients without movement disorders or seizures were evaluated for neurotransmitter abnormalities resulting in combinations of

Table 3: Anti seizure medications and CSF neurotransmitter abnormalities

\begin{tabular}{l|c|c|c|c|c|c}
\hline & Low HVA & Low 5-HIAA & Low HVA + 5-HIAA & Low MTHF & Low MTHF + HVA & Low MTHF + HVA + 5-HIAA \\
\hline Keppra & 4 & 3 & 2 & 1 & 1 & 1 \\
\hline VPA & 2 & 2 & 4 & 1 & 2 & 1 \\
\hline Phenobarb & 3 & 1 & & 1 & & 1 \\
\hline Topiramate & 4 & & 2 & 2 & & \\
\hline Clobazam & 2 & 1 & & & & \\
\hline Vigabatrin & 4 & 1 & 2 & 1 & & \\
\hline Lamotrigine & 1 & & & & & \\
\hline Clonazepam & 2 & & & & & \\
\hline Carbamazepine & 2 & & & & & \\
\hline
\end{tabular}




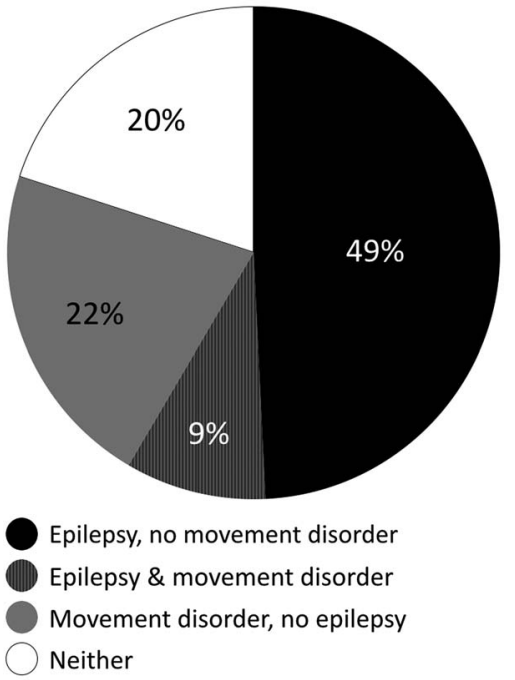

Figure 3: Percentage of patients with movement disorder, epilepsy, both or neither.

Black: epilepsy, no movement disorder; Striped: epilepsy and movement disorder; Grey: movement disorder, no epilepsy; White: neither epilepsy nor movement disorder

developmental delay, abnormal tone, autism, and failure to thrive. The dependent relationship between epilepsy and absence of movement disorder was significant $(\mathrm{p}=0.0019$, chi-square test). The odds ratio (OR) for epilepsy given the presence of a movement disorder was 0.17 .

MRI scan abnormalities were present in 37 of the 64 patients (56\%, Table 1) and 20 of the 37 patients with epilepsy (54\%). There was not a significant relationship between the presence of epilepsy and the presence of MRI abnormalities $(p=0.18)$. The types of abnormalities are summarized in Table 4 . There was not a significant difference in the presence or absence of MRI abnormalities depending on the type of neurotransmitter deficiency ( $\mathrm{p}=0.5$, calculated comparing low HVA vs. low HVA and 5-HIAA; other categories had insufficient numbers). It is of note that neurotransmitter abnormalities were seen more commonly $(42 \%)$ in abnormalities of white matter than in primary gray matter $(22 \%)$ abnormalities, an observation that may be of interest in future research. There was also no significant relationship

Table 4: Types of MRI abnormalities in patients with abnormal CSF neurotransmitters

\begin{tabular}{l|c}
\hline MRI abnormality & Number, $(\%)$ \\
\hline White matter signal abnormalities & $15(39 \%)$ \\
\hline Ventriculomegaly & $8(20.5 \%)$ \\
\hline Global atrophy & $7(18 \%)$ \\
\hline Ischemic changes or encephalomalacia & $6(15.3 \%)$ \\
\hline Delayed myelination & $5(12.8 \%)$ \\
\hline Cerebellar atrophy & $4(10.2 \%)$ \\
\hline Basal ganglia abnormalities & $3(7.7 \%)$ \\
\hline White matter atrophy & $2(5.1 \%)$ \\
\hline Cortical dysplasia & $2(5.1 \%)$ \\
\hline
\end{tabular}

between type of MRI scan abnormality and the presence or absence of a movement disorder $(\mathrm{p}=0.2)$.

A movement disorder was present in 20 of 64 patients with abnormal neurotransmitters $(31 \%)$. These included tremor in six patients $(30 \%)$, hyperkinetic movement disorder in three $(15 \%)$, dystonia in three (15\%), myoclonus in two (10\%), and dyskinesia in two $(10 \%)$. In the remaining four patients, the movement disorder was insufficiently described in the consult letter. There was not a significant relationship between the type of neurotransmitter deficiency and the presence or absence of a movement disorder ( $p=0.19$, calculated comparing low HVA vs. low HVA and 5-HIAA; other categories had insufficient numbers). There was a significant negative relationship between movement disorders and the presence of epilepsy.

In the 16 patients with neither movement disorders nor epilepsy, indications for CSF neurotransmitter assessment included a combination of developmental delay and single seizure, hypotonia, autonomic dysfunction, or autism.

\section{DISCUSSION}

Dopamine functions in the brain as a neurotransmitter involved in fluidity of movement, cognition, as well as motivation and reward. ${ }^{20}$ Serotonin is important in regulating pain, sleep, appetite, and gut motility, amongst other autonomic functions, as well as cognition and psychiatric states such as anxiety, depression, and agitation. ${ }^{21}$ Of the 376 patients over a 5-year period who underwent CSF neurotransmitter analysis for a variety of indications including movement disorders, epileptic encephalopathy, and severe neurodevelopmental delay, a considerable proportion (17.2\%) had abnormalities secondary to other disorders. It might be anticipated from the literature that movement disorders would be the most common neurologic condition associated with neurotransmitter abnormalities; however, among our series, seizures were more frequent $(59 \%$ of patients) than movement disorders $(31 \%)$. This is likely from several factors, including the higher prevalence of epilepsy compared with movement disorders in the pediatric population seen in the neurology clinics, and the local practice of performing neurotransmitter analysis on all patients with infantile spasms and other severe infantile epileptic encephalopathies. Other characteristics that may prompt neurotransmitter assessment of patients with epilepsy in our center include associated abnormal tone, developmental delay, and autonomic disturbances. One could hypothesize that movement disorders are underrecognized and underreported in clinical symptom summaries, but all patients were examined by pediatric neurologists, and we trust that the clinical reports are accurate. In the literature, the relationship between seizures in patients and secondary monoamine abnormalities has been inconsistent (Table 4).

Much of the literature regarding monoamines and seizures is in the context of epileptic encephalopathy syndromes such as West and Ohtahara (Table 5). Decreased HVA was the most consistent neurotransmitter abnormality across studies, ${ }^{7,11,22,23}$ and, in our series with epileptic encephalopathy, 9 (47\%) had low HVA in isolation (average, $86 \%$ lower limit of normal; range, 60\%-98\%), and, including those with another NT abnormality, $13(72 \%)$ had low HVA (average, 82\% lower limit of normal; range, $38 \%-98 \%$ ). Significantly lower levels of 5-HIAA and HVA were described in seven infants with infantile spasms by Langlais et al., ${ }^{11}$ and, in a series by Assmann, two patients with 
Table 5: CSF 5-HIAA and HVA in epilepsy: a review of the literature

\begin{tabular}{|c|c|c|c|c|c|}
\hline CSF monoamine studies & Epilepsy Type & $\mathbf{n}$ & HVA & 5-HIAA & Treatment \& outcome \\
\hline Reynolds (1975) & No specification & 42 & $\uparrow$ & $\uparrow$ & $\begin{array}{l}\text { Increased 5-HIAA and HVA in treated epileptics vs. untreated and } \\
\text { controls }\end{array}$ \\
\hline Molero-Luis et al 2013 & No specification & 740 & No pattern & Not measured & N/A \\
\hline Giroud (1990) & Febrile & 24 & $\downarrow$ & $\downarrow$ & \\
\hline \multirow[t]{2}{*}{ Devinsky et al 1992} & Generalized & 7 & No change & No change & N/A \\
\hline & Focal & 18 & $\uparrow$ postictal & No change & N/A \\
\hline $\begin{array}{l}\text { Naffah-Mazzacoratti et al } \\
1996\end{array}$ & Focal & 6 & $\uparrow$ & $\uparrow$ & N/A \\
\hline Louw (1989) & Focal (intractable & 14 & $\uparrow$ & $\uparrow$ & \\
\hline \multirow[t]{2}{*}{ Echenne et al 2008} & Focal & 14 & Normal & Normal & N/A \\
\hline & Encephalopathy & 23 & Normal & Normal & N/A \\
\hline Duarte et al 2008 & Encephalopathy & 23 & $\uparrow(1)$ & $\uparrow(2)$ & High neopterin associated with mortality (seen in Ohtahara) \\
\hline García-Cazorla et al 2007 & Encephalopathy & 29 & $\downarrow(3)$ & No change & 3 HVA deficient died; no relationship with AEDs \\
\hline Langlais et al 1991 & Encephalopathy & 7 & $\downarrow$ & $\downarrow$ & 5 -HIAA increased in responders to steroids $(5 / 7)$ \\
\hline De Grandis 2010 & Epileptic encephalopathy & 19 & Not measured & $\downarrow$ & \\
\hline \multirow[t]{2}{*}{ Van Der Heyden 2003} & West Syndrome & 2 & $\downarrow$ & Not measured & \\
\hline & Unspecified & 3 & $\downarrow$ & Not measured & \\
\hline \multirow[t]{2}{*}{ Assmann, B. 2006) } & Encephalopathy & 2 & $\downarrow(2)$ & $\downarrow(1)$ & Repeat test in patient with treated spasms $=$ resolution of $\downarrow$ HVA \\
\hline & Generalized & 2 & $\begin{array}{l}\uparrow(1) \\
\downarrow(1)\end{array}$ & $\begin{array}{l}\uparrow(1) \\
\downarrow(1)\end{array}$ & N/A \\
\hline Dahlin et al 2012 & $\begin{array}{l}\text { Generalized (21), Encephalopathy } \\
\text { (13) } \\
\text { Focal (5) }\end{array}$ & 26 & $\begin{array}{l}\text { Average } \\
\text { normal }\end{array}$ & $\begin{array}{c}\text { Average } \\
\text { normal }\end{array}$ & HVA and 5-HIAA decreased by diet \\
\hline
\end{tabular}

encephalopathy had decreased HVA and one also had decreased 5-HIAA. ${ }^{23}$ The cooccurrence of HVA and 5-HIAA abnormalities as secondary disturbances of monoamine metabolism has been previously noted. ${ }^{6}$ In our patients with epileptic encephalopathy, only three of $18(16.7 \%)$ were deficient in both HVA and 5-HIAA (average, 65\% normal value of HVA; range, 38\%-84\%; average, $69 \%$ normal value of 5-HIAA; range, 41\%-96\%). Epileptic encephalopathy was associated with higher mortality in our study: two of 18 patients with epileptic encephalopathy (11.1\%) are known to be deceased, an association likely resulting from the severity of their underlying disorders (one died at the age of 3 days, one at 3 years; both with severe undiagnosed conditions and both had low HVA in isolation). Of 29 patients described by Garcia-Cazorla et al. with epileptic encephalopathies, 3 infants had HVA deficiency, all of whom died. ${ }^{22}$ It is unclear whether disorders of neurotransmission contribute to mortality in epileptic encephalopathy. A series by Echenne et al. of 23 patients with a variety of epileptic encephalopathies did not identify any disorders of CSF monoamines. ${ }^{24}$

Compared with epileptic encephalopathy, there is a less clear trend in the literature toward an increase or decrease of dopamine metabolites in the setting of episodic seizures, although they tended to be higher in studies of focal seizures and acute seizures. Increased dopamine was found in a study of 6 adult patients with focal epilepsy refractory to medications, ${ }^{25}$ and CSF HVA was significantly higher following a focal seizure but not after a generalized tonic clonic seizure in a series of 18 patients. ${ }^{13}$ No change in dopamine metabolites was found in 893 patients with abnormal EEGs, of which 740 had epilepsy ${ }^{8}$ and 14 with focal epilepsy in another series had HVA in the normal range. ${ }^{24}$ Decreased dopamine metabolites were found in 21 patients from a cohort of 448 by Van Der Heyden et al., ${ }^{7}$ two of whom had West syndrome and three of whom had other seizure types. Two thirds of patients with low dopamine experienced epilepsy in our study. With regard to seizure severity and HVA, Devinsky et al. found higher levels of HVA following focal dyscognitive seizures, ${ }^{13}$ and higher levels of HVA were found in the hippocampi of rats following pilocarpine induced seizures. ${ }^{26}$ There was no difference in HVA deficiency in those with controlled versus uncontrolled seizures in our group. In addition, information was not available on the proximity of data collection to seizure timing.

In the setting of episodic seizures the literature is inconclusive regarding serotonin. Increased serotonin was observed in six adult patients with focal epilepsy refractory to medications. ${ }^{25}$ Conversely, no change in serotonin was found in 24 patients with epilepsy in the postictal or interictal period compared with controls ${ }^{13} ; 14$ pediatric patients with focal epilepsy had average 5HIAA values in the normal range. ${ }^{24}$ Decreased serotonin in 117 patients without congenital neurotransmitter disorders was associated with epilepsy or epileptic encephalopathy in one quarter. ${ }^{6}$ The multitude of locations and actions of the greater than ten serotonin receptor subtypes is a formidable challenge in establishing a clear relationship. Abnormal values in systemically unwell patients support the sensitivity of this system to general metabolic derangement.

There are few data available on treatment of secondary neurotransmitter deficiency in the context of epilepsy, with one case of dopamine replacement therapy in infantile spasms 
described. ${ }^{23}$ One patient in our cohort with $S C N 2 A$ mutation and low levels of CSF biogenic amines was supplemented with L-dopa/ carbidopa and 5-hydroxytryptophan with moderate improvement in his seizure control. ${ }^{4}$ Langlais found that, in infants with epileptic encephalopathy, 5-HIAA levels increased in the five of seven patients who responded to steroids, ${ }^{11}$ whereas Takeuchi found no change. ${ }^{24}$ Two studies examining systemic serotonin alterations in response to antiepileptic medications demonstrated that there was a significant increase in 12 children treated with topiramate monotherapy, ${ }^{25}$ whereas in 16 patients, lamotrigine add-on therapy resulted in decreased plasma serotonin. ${ }^{26}$

In patients with secondary NT deficiencies with poorly controlled seizures and/or movement disorder, monoamine replacement may be of benefit, but further studies are indicated to generate more solid evidence for this.

\section{Limitations}

This is a retrospective case series; thus, the available information is limited by availability of details in the chart. The total number of patients is limited, and there might be selection bias for diagnostic lumbar puncture; it is more likely that severely affected children with undiagnosed disease will undergo this procedure. The number of NT metabolites measured is limited (e.g. no GABA, glutamate). Also the technique with which the lumber puncture is done and the CSF collected may influence results. We acknowledge that the clinical information regarding the timing of seizures in relation to CSF collection is crucial for a more comprehensive interpretation of results, but given the retrospective nature of this study along with logistical challenges in the clinical setting, this was not possible. The results of the current study may allow us to obtain the resources to perform such a prospective study.

\section{CONCLUSIONS}

Acknowledging the limitations of this retrospective study, we report neurotransmitter abnormalities in one of six patients with neurologic abnormalities in whom CSF was analyzed over a 5 -year period. Only two $(0.53 \%)$ of these patients were diagnosed with a primary congenital neurotransmitter disorder; in 11 patients $(16.9 \%)$, another genetic condition was identified, whereas in more than $85 \%$, etiology of their biochemical and clinical symptoms remained unknown despite a thorough evaluation. One-third of our patients with neurotransmitter disorders suffered from movement disorders, and more than half had epilepsy, the most common type being epileptic encephalopathy. There was no relationship between the presence or severity of epilepsy or its amenability to treatment, in patient and the type or severity of monoamine derangement identified; this conclusion is similar to previous publications.

Epilepsy was more common with isolated deficiencies of HVA and 5-HIAA, and movement disorder was more common in a combined deficiency; however, the difference was not significant. In patients with abnormal neurotransmitter profiles, epilepsy and movement disorders rarely copresented. In addition, the pathophysiology of the relationship between monoamines and epilepsy in humans is unclear, except perhaps in epilepsies caused by mutations in certain ion channels or ATPase pumps, when the change in electric gradient and action potential prevents voltagegated calcium channel activation, and neurotransmitter release from vesicles. ${ }^{4}$
Future research is needed to further elucidate relation between epilepsy and CSF monoamine and other neurotransmitter metabolite profiles and should be done via carefully designed prospective case series of all results from patients with epilepsy who underwent lumbar puncture, including the relation with timing of seizures, the morphology of their EEG tracing, and the type and last dose of antiepileptic drugs. Such data will allow reliable comparison between epilepsy patients with normal versus abnormal CSF neurotransmitter results. Other important data could also be collected, such as sleep disorders, to assess for prevalence of low 5HIAA levels in these patients. There is a possible role for dopamine and/or serotonin replacement therapy in patients with secondary biogenic amine deficiencies, ${ }^{4}$ but this requires more research and evidence to draw meaningful conclusions or recommendations.

\section{ACKNOWLEDGMents AND FUnding}

We are grateful to our colleagues in BC Children's Hospital, University of British Columbia, Vancouver, Canada: Dr. H. Vallance and Dr. G. Sinclair (Biochemical Genetics Laboratory, Department of Pathology and Laboratory Medicine) for interpretation of laboratory results and our colleagues in the Divisions of Pediatric Neurology and Biochemical Diseases (Department of Pediatrics) for diagnostic evaluation and management of these patients; Dr. M. Sargent and Dr. K. Poskitt (Department of Radiology) for neuroimaging interpretation. We also thank Dr. C.J. Ross, Mr. C. Shyr, Dr. M. Tarailo-Graovac, and Dr. W. Wasserman (Centre for Molecular Medicine \& Therapeutics, Department of Medical Genetics, University of British Columbia) for bioinformatic analyses.

This study was part of the BC Children's Hospital Foundationfunded 1st Collaborative Area of Innovation (www.tidebc.org). CDMvK is the recipient of the Michael Smith Foundation for Health Research scholar award.

\section{Disclosures}

CDMvK reports grants from the Michael Smith Foundation for Health Research and the BC Children's Hospital Foundation during the conduct of the study. The remaining authors have nothing to disclose.

The study was approved by the Regional Ethics Board, BC Children's Hospital, University of British Columbia (H11-01142).

\section{REFERENCES}

1. Hyland K. Presentation, diagnosis, and treatment of the disorders of monoamine neurotransmitter metabolism. Semin Perinatol. 1999;23:194-203.

2. Leach EL, Shevell M, Bowden K, Stockler-Ipsiroglu S, van Karnebeek C. Treatable inborn errors of metabolism presenting as cerebral palsy mimics: systematic literature review. Orphanet J Rare Dis. 2014;9:197.

3. Marecos C, Ng J, Kurian MA. What is new for monoamine neurotransmitter disorders? J Inherit Metab Dis. 2014;37:619-26.

4. Horvath GA, Demos M, Shyr C, Matthews A, Zhang L, Race S, et al. Secondary neurotransmitter deficiencies in epilepsy caused by voltage-gated sodium channelopathies: A potential treatment target? Mol Genet Metab. 2016;117:42-8.

5. Mercimek-Mahmutoglu S, Sidky S, Hyland K, Patel J, Donner E, Logan W, et al. Prevalence of inherited neurotransmitter disorders in patients with movement disorders and epilepsy: a retrospective cohort study. Orphanet J Rare Dis. 2015;10:1051-20. 
6. De Grandis E, Serrano M, Pérez-Dueñas B, Ormazabal A, Montero R, Veneselli E, et al. Cerebrospinal fluid alterations of the serotonin product, 5-hydroxyindolacetic acid, in neurological disorders. J Inherit Metab Dis. 2010;33:803-9.

7. Van Der Heyden JC, Rotteveel JJ, Wevers RA. Decreased homovanillic acid concentrations in cerebrospinal fluid in children without a known defect in dopamine metabolism. Eur J Paediatr Neurol. 2003;7:31-7.

8. Molero-Luis M, Serrano M, Ormazabal A, Pérez-Dueñas B, García-Cazorla A, Pons R, et al. Homovanillic acid in cerebrospinal fluid of 1388 children with neurological disorders. Dev Med Child Neurol. 2013;55:559-66.

9. Hirtz D, Thurman DJ, Gwinn-Hardy K, Mohamed M, Chaudhuri AR, Zalutsky R. How common are the "common" neurologic disorders? Neurology. 2007;68:326-37.

10. Giroud M, Dumas R, Dauvergne M, d'Athis P, Rochette L, Beley A, et al. 5-Hydroxyindoleacetic acid and homovanillic acid in cerebrospinal fluid of children with febrile convulsions. Epilepsia. 1990;31:178-81.

11. Langlais PJ, Wardlow ML, Yamamoto H. Changes in CSF neurotransmitters in infantile spasms. Pediatr Neurol. 1991;7:440-5.

12. Rocha L, Alonso-Vanegas M, Villeda-Hernández J, Mújica M, Cisneros-Franco JM, López-Gómez $M$, et al. Dopamine abnormalities in the neocortex of patients with temporal lobe epilepsy. Neurobiol Disease. 2012;45:499-507.

13. Devinsky O, Emoto S, Goldstein DS, Stull R, Porter RJ, Theodore WH, et al. Cerebrospinal fluid and serum levels of dopa, catechols, and monoamine metabolites in patients with epilepsy. Epilepsia. 1992;33:263-70.

14. Hyland $\mathrm{K}$. The lumbar puncture for diagnosis of pediatric neurotransmitter diseases. Ann Neurol. 2003;54(Suppl 6):S13-7.

15. Hyland K, Surtees RA, Heales SJ, Bowron A, Howells DW, Smith I. Cerebrospinal fluid concentrations of pterins and metabolites of serotonin and dopamine in a pediatric reference population. Pediatr Res. 1993;34:10-4.
16. Hyland K. Clinical utility of monoamine neurotransmitter metabolite analysis in cerebrospinal fluid. Clin Chem. 2008; 54:633-41.

17. Fisher RS, Acevedo C, Arzimanoglou A, Bogacz A, Cross JH, Elger CE, et al. ILAE official report: a practical clinical definition of epilepsy. Epilepsia. 2014;55:475-82.

18. Berg AT, Berkovic SF, Brodie MJ, Buchhalter J, Cross JH, van Emde Boas W, et al. Revised terminology and concepts for organization of seizures and epilepsies: report of the ILAE Commission on Classification and Terminology, 2005-2009. Epilepsia. 2010;51:676-85.

19. Berg AT, Shinnar S, Levy SR, Testa FM, Smith-Rapaport S, Beckerman B. Early development of intractable epilepsy in children: a prospective study. Neurology. 2001;56:1445-52.

20. Schultz W. Multiple dopamine functions at different time courses. Annu Rev Neurosci. 2007;30:259-88.

21. Drugs acting on 5-hydroxytryptamine receptors. Lancet. 1989;2:717-9.

22. García-Cazorla A, Serrano M, Pérez-Dueñas B, Gonzalez V, Ormazabal A, Pineda M, et al. Secondary abnormalities of neurotransmitters in infants with neurological disorders. Dev Med Child Neurol. 2007;49:740-4.

23. Assmann B. Biogenic amines and pterins in cerebrospinal fluid: some pitfalls with interpretation. Future Neurol. 2006;1: 651-657.

24. Echenne B, Roubertie A, Leydet J, Rivier F, Hoffmann GF. Monoamine metabolism study in severe, early-onset epilepsy in childhood. Epileptic Disord. 2008;10:130-5.

25. Naffah-Mazzacoratti MG, Amado D, Cukiert A, Gronich G, Marino $\mathrm{R}$, Calderazzo L, et al. Monoamines and their metabolites in cerebrospinal fluid and temporal cortex of epileptic patients. Epilepsy Res. 1996;25:133-7.

26. Freitas RM, Vasconcelos SMM, Souza FCF, Viana GSB, Fonteles MMF. Monoamine levels after pilocarpine-induced status epilepticus in hippocampus and frontal cortex of Wistar rats. Neurosci Lett. 2004;370:196-200. 